\title{
Quantifying Ecological Performance of Giant Panda Conservation: Evidence from Sichuan Province
}

\author{
Zhenjiang Song ${ }^{1}\left[\right.$ and $\mathrm{Yi} \mathrm{Li}^{2, *}$ \\ 1 Institute of New Rural Development, College of Economics and Management, Jiangxi Agricultural University, \\ Nanchang 330045, China; tgsongzhenjiang@126.com \\ 2 College of Economics and Management, South China Agricultural University, Guangzhou 510642, China \\ * Correspondence: xiaoyi1983524@126.com; Tel.: +86-139-2228-0524
}

Citation: Song, Z.; Li, Y. Quantifying Ecological Performance of Giant Panda Conservation: Evidence from Sichuan Province. Forests 2021, 12, 1701. https://doi.org/10.3390/ f12121701

Academic Editor: Yaoqi Zhang

Received: 9 October 2021

Accepted: 2 December 2021

Published: 4 December 2021

Publisher's Note: MDPI stays neutral with regard to jurisdictional claims in published maps and institutional affiliations.

Copyright: (c) 2021 by the authors. Licensee MDPI, Basel, Switzerland. This article is an open access article distributed under the terms and conditions of the Creative Commons Attribution (CC BY) license (https:/ / creativecommons.org/licenses/by/ $4.0 /)$.

\begin{abstract}
The giant panda (Ailuropoda melanoleuca) is a symbolic and flagship species in the field of endangered wildlife conservation. We studied the changing and driving factors of landscape patterns in Sichuan giant panda habitats through image interpretation and ecological niche evaluation models. According to land-use and cover-change analysis, we also studied the structural changes in habitat over the past two decades and used empirical analysis to evaluate the relative ecological niche widths and overlap of giant panda distribution areas in 1995 and 2015. It is found the area of non-forested land decreased significantly from 1995 to 2015. It is interesting that the high-quality land-use types tended to decrease but low/middle-quality land-use types tended to increase over the past 20 years. Giant panda conservation projects in China have promoted changes in conservation thought and management, as well as the innovation of technical means over the studied period. The goals of Chinese giant panda conservation projects are not only to facilitate giant panda reproduction but also to alleviate the contradiction between conservation and development and promote the coexistence of humans and giant pandas.
\end{abstract}

Keywords: giant panda; landscape pattern; habitat quality; ecological niche evaluation model; driving factor

\section{Introduction}

The giant panda (Ailuropoda melanoleuca) is a symbolic and flagship species in the field of endangered wildlife conservation [1]. Giant panda nature reserves serve as survival and reproductive shelters for giant pandas but also human habitations [2,3]. The resource utilization of human beings often disturbs panda habitat, even though regulations have imposed tightly restricted resource utilization [4]. The first giant panda nature reserve was established in Gansu Province in 1963. The population size of giant pandas is growing, their area of habitat is continuously expanding. Since the 21st century, China has made great achievements in giant panda conservation. During the period of the 3rd National Survey (1989-2002), 23,049 $\mathrm{km}^{2}$ of giant panda habitat was protected [5]. During the period of the 4th National Survey (2003-2014) on Giant Panda in China, 25,765 km² giant panda habitat was discovered [6-8], representing an 11.78\% increase. Currently, 67 giant panda nature reserves are distributed in the alpine valleys of Sichuan, Shaanxi, and Gansu, covering approximately 33,600 km² [9], with the aim of protecting the estimated 1864 giant pandas living in the wild [6-8]. These data show that giant panda conservation projects have achieved dramatic results. It is rare for a country to establish such large-scale nature reserves for the protection of a single species.

Giant panda nature reserves contribute to the protection of not just pandas but natural resources in general, supplementing the existing nature reserve system in China. Research shows that some significant differences in niche-overlap indices among giant panda sympatric species. The width of environmental niches of sympatric species almost completely encompasses that of the giant panda, which indicates that giant panda conservation may 
contribute to the coexistence of sympatric species in the same space [10-12]. Despite the significant progress that has been made, many challenges still exist regarding the conservation of giant pandas. The isotopic, trophic, and ecological niche widths of ancient pandas are approximately three times larger than those of modern pandas, suggesting that ancient pandas are constrained by diet. Therefore, habitat contraction is constrained by the distribution of bamboo for giant pandas [13]. Since modern times, giant panda habitats have been distributed in moderate to high bamboo densities, mid elevations, both primary and secondary forests, and areas more distant from human activities [14]. Although 67 giant panda nature reserves have been established in China, the activity of the giant panda population is dynamic [15]. At present, approximately one third of the wild population of giant pandas and $46 \%$ of their habitats are not included in the reserve system. In addition, the contradiction between conservation and development still exists, such as habitat fragmentation caused by human activities [16-18] and habitat degradation caused by the use of natural resources by rural households (planting, cutting firewood, gathering plants/berries, etc.) [19-24]. Reserves and communities have conflicting interests over ecological protection and economic development $[25,26]$. Meanwhile, a series of natural and social factors are driving changes in habitat landscape patterns, including weather $[27,28]$ and geology $[4,29]$. Human disturbance and natural disasters have aggravated habitat contraction.

Multiple subjects focus on the quantification of the ecological performance of giant panda conservation. Ecologists have measured the ecological performance of giant panda conservation through the ecological niche evaluation model and various other means $[30,31]$. Economists have focused on the contradiction between ecological protection and economic development by measuring the endowment of natural resources and the impact of household behaviour on habitats [32-34]. Geologists have analyzed the conservation level of giant pandas by LUCC $[4,35]$. From an interdisciplinary perspective, the structure of habitat landscape is studied by LUCC, analyzing the level of giant panda habitat in different historical periods using the ecological niche evaluation model. By ecological-niche factor analysis, we explore the mechanisms of giant panda habitat evolution in order to reveal ecological performance.

\section{Study Area}

The study area is giant panda distribution areas in Sichuan Province, which include 36 counties. The area includes habitat and potential habitat of giant pandas. The largest populations of the giant panda are in this area, which protects 1378 wild giant pandas. Traditionally, the study of giant panda habitat has usually adopted the boundary of nature reserves as the evaluation scope, unable to exclude the disturbance caused by resourceutilization activities of people who live in the areas surrounding the nature reserves. Furthermore, the boundaries of giant panda habitats are dynamic. The adjustment of nature reserves always involves time lags that are usually slower than the change in the activity track of the pandas. Although Chinese giant panda nature reserves cover a total area of $33,600 \mathrm{~km}^{2}$, only $25,766 \mathrm{~km}^{2}$ represents panda habitat [6-8]. Many activity areas of the giant panda are not included in the nature reserves (as shown in Figure 1). In addition, large areas of many counties have been classified as part of the Chinese Giant Panda National Park, including Baoxing County (92.80\%), Tianquan County $(70.40 \%)$, and Wenchuan County (68.50\%). Therefore, this paper will adopt counties with giant panda habitat as evaluation units to reveal the changing mechanisms of landscape patterns in Sichuan giant panda habitats. 
A

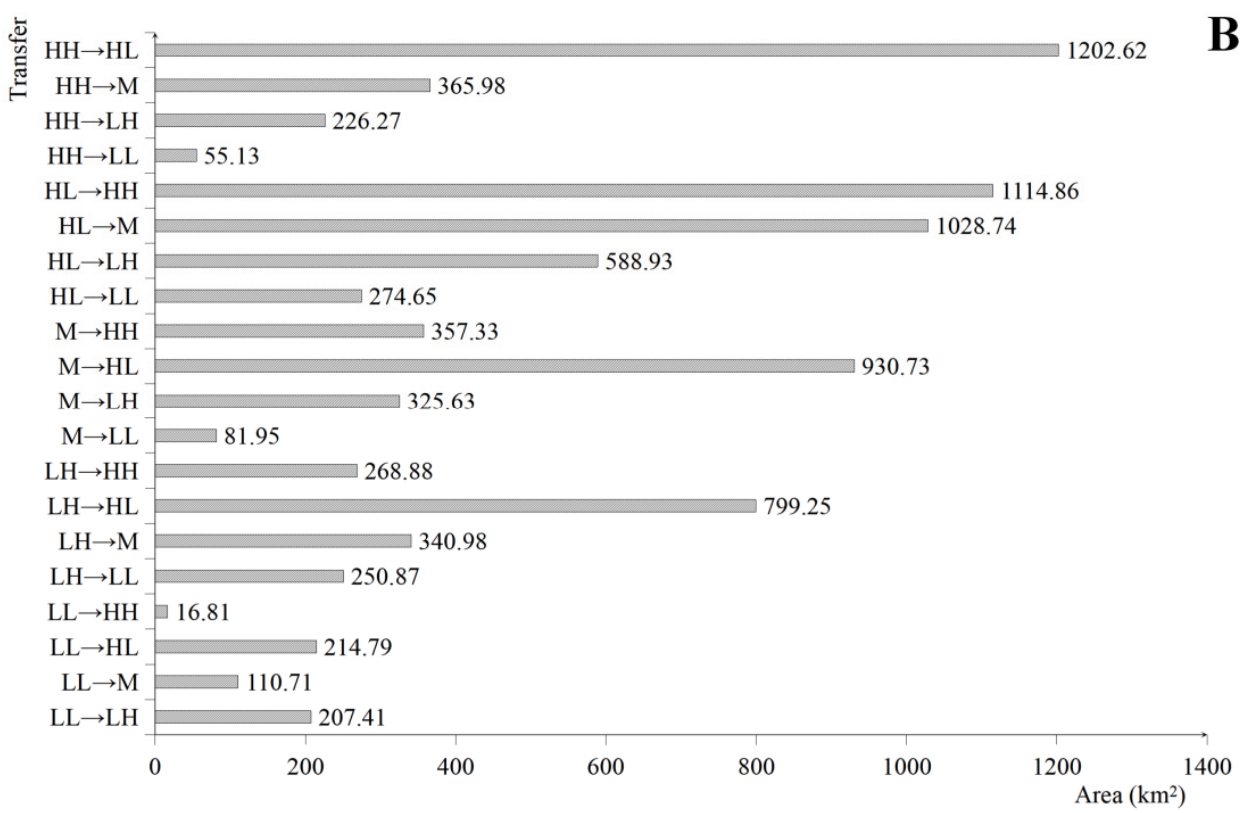

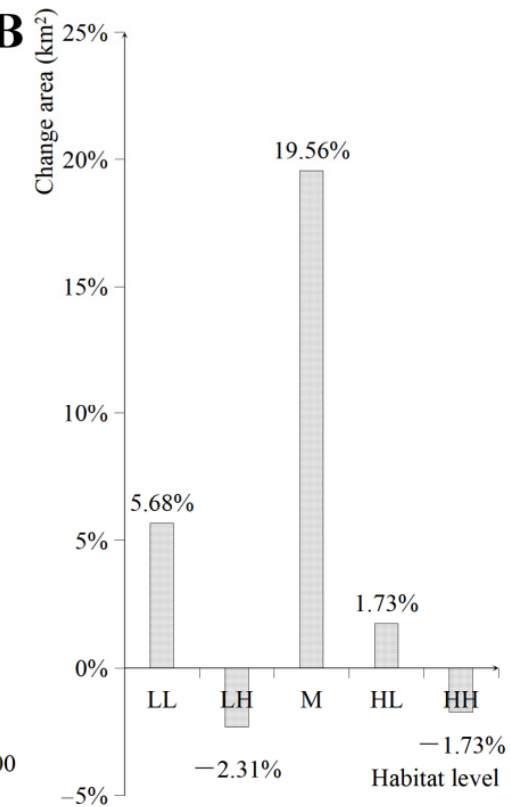

Figure 1. General change in giant panda habitat between 1995 and 2015: (A) change in transfer area among different levels of giant panda habitat quality over the past two decades; (B) change in area of different giant panda habitat quality classes over the past two decades.

This study area includes its unique natural and social factors. Sichuan Province represents a transitional zone of landform and physiognomy. Orogeny drives the shape of mountain chains, and the Longmenshan fault zone passes through Sichuan Province. However, frequent crustal activities occur in the study area, which leads to changes in landscape patterns. Such changes can also have negative effects on biodiversity [29]. During the Wenchuan earthquake of 2008, the giant panda habitat experienced a large disruption. The study areas are located on the border between the subtropical and plateau climate zones. Regional temperature and precipitation have an effect on the growth of bamboo. Thus, this study could reveal the internal mechanisms of the impact of climatic factors on changes in giant panda habitats. On the other hand, most giant panda habitats in Sichuan Province are located in multinational and concentrated poverty regions (as shown in Figures 2 and 3). Farmers generally show resource dependence in these areas; their food comes from cultivated land, and their firewood comes from forestland. However, these activities often disturb the habitat of the giant panda. Therefore, the resource utilization behavior of the minority and poverty-stricken populations could place pressure on giant panda conservation. This information indicates that Sichuan giant panda habitats represent typical regions, displaying a series of environmental-conflict and resource-utilization contradictions. Consequently, this paper considers counties with giant panda habitat in Sichuan Province as the study region. 


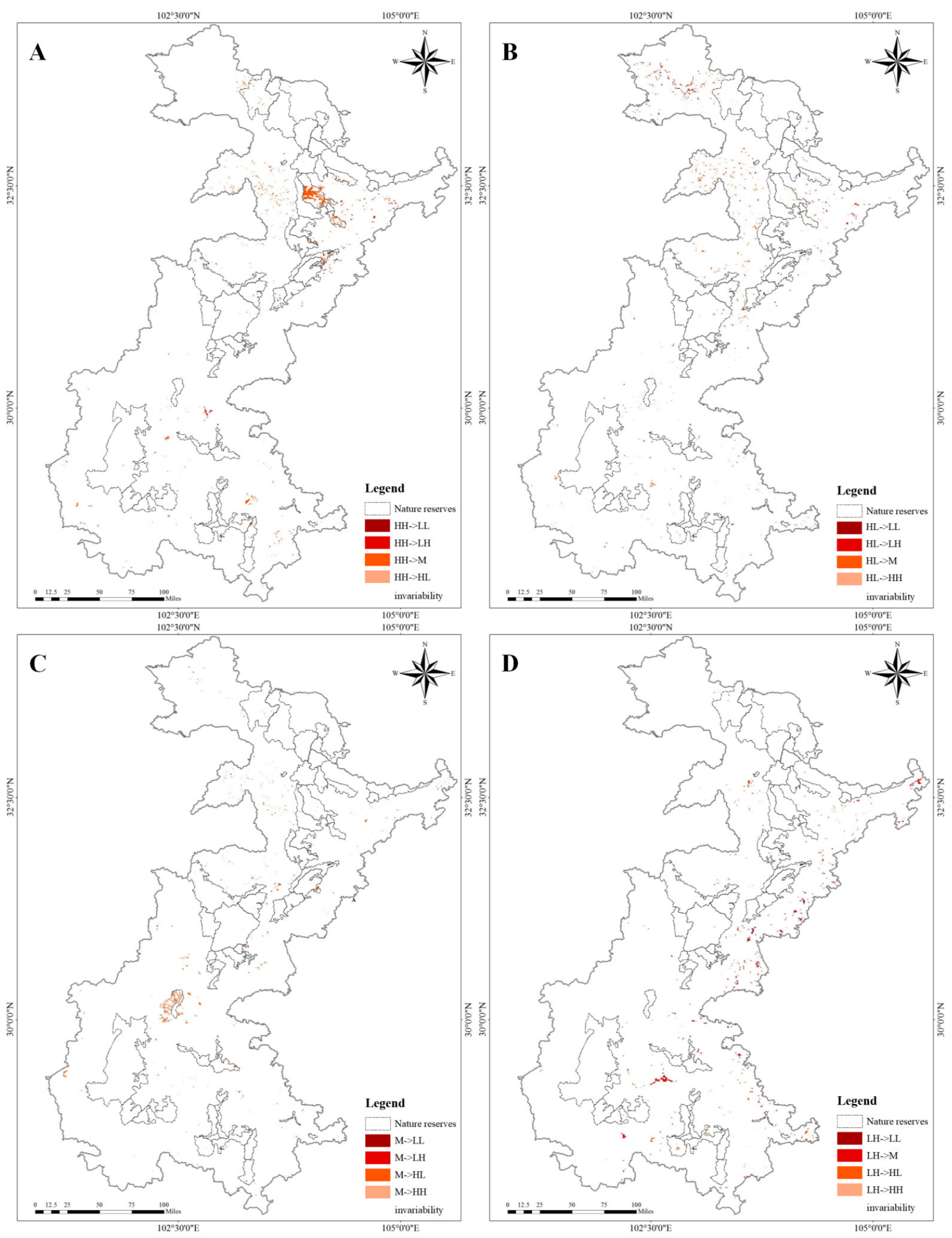

Figure 2. Cont. 

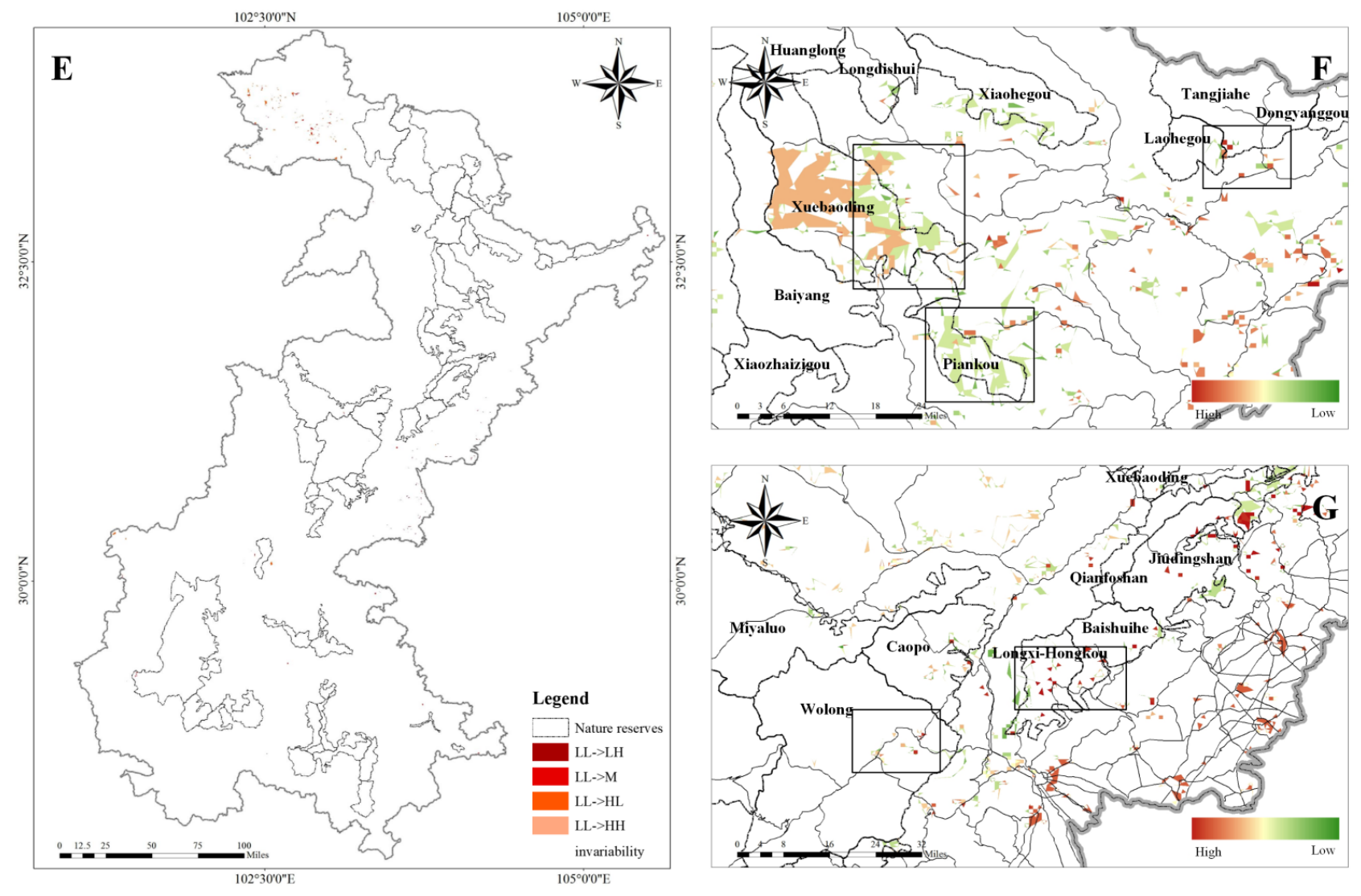

Figure 2. Conversion of different habitat types between 1995 and 2015. Notes: (1) Maps (A-E) show the conversion between different habitat types in the past two decades. (2) The maps $(\mathbf{F}, \mathbf{G})$ with large areas of variation in the past two decades.

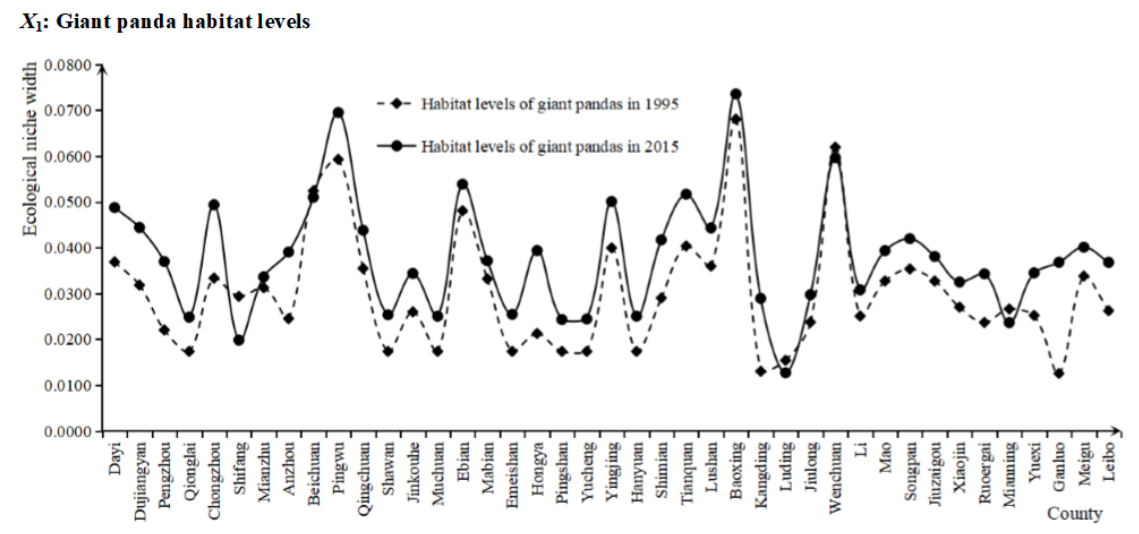

$X_{2}$ : Support force levels of giant pandas

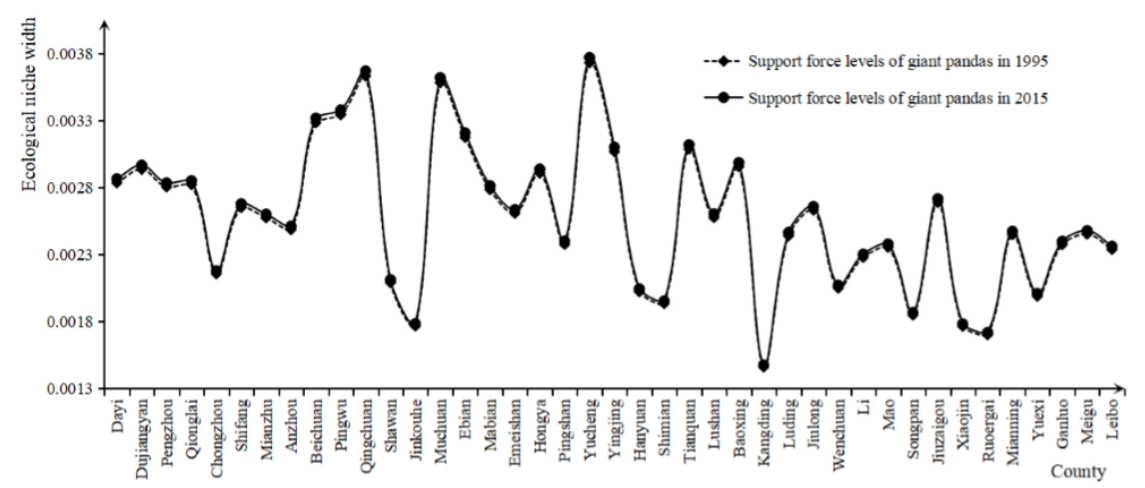

Figure 3. Cont. 

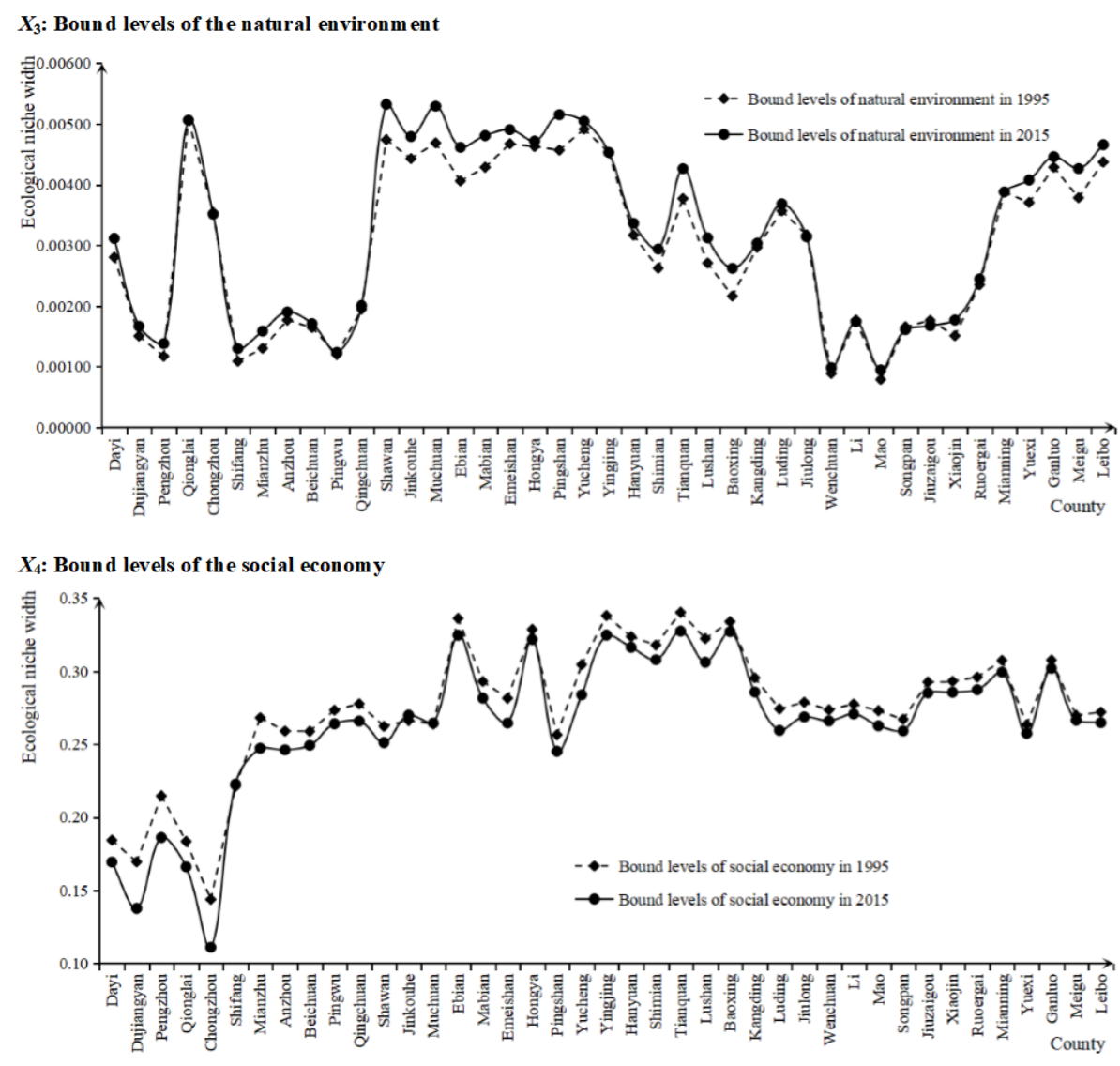

Figure 3. Relative ecological niche widths of Sichuan giant panda distribution areas in 1995 and 2015: $\left(X_{1}\right)$ : Giant panda habitat levels. $\left(X_{2}\right)$ : Support force levels of giant pandas. $\left(X_{3}\right)$ : Bound levels of the natural environment. $\left(X_{4}\right)$ : Bound levels of the social economy. Notes: (1) The relative ecological niche widths of Sichuan giant panda distribution areas in 2015 are generally higher than those in 1995. (2) The high giant panda habitat levels are distributed in national protection areas, such as Pingwu, Baoxing, and Wenchuan. The high support force levels of giant pandas are distributed at the edges of habitat, such as in Qingchuan, Muchuan, and Yucheng. The high bound levels of giant pandas are distributed in the alpine valley region, such as Qionglai, Shawan, and Muchuan. The high bound levels of the social economy are distributed in multi-nationality and concentrated contiguous extreme poverty areas, such as Baoxing, Shimian, and Hanyuan.

\section{Data and Methods}

\subsection{Data Collection}

Land-use and cover-change (LUCC) data for 36 counties containing giant panda habitat obtained from 1995 to 2015 were collected from the Resource and Environment Data Cloud Platform in the form of remote sensing Landsat Thematic Mapper (TM)/Enhanced Thematic Mapper (ETM) images (https:/ / www.resdc.cn/data.aspx?DATAID=96 (accessed on 10 October 2021)) A land-use transfer matrix was built to analyse the dynamic changes in landscape types. The meteorological data were obtained from 2400 meteorological stations (http:/ / data.cma.cn/data/detail/dataCode/A.0012.0001.html (accessed on 10 October 2021)). The processing of meteorological data was based on the spatial interpolation technique, which relied on ANUSPLIN software [36]. The demographic data (http://www.resdc.cn/DOI (accessed on 10 October 2021)) were expressed on the basis of population spatialization with spatial statistical units. The formula also considered a series of related factors, such as land-use patterns, the intensity of night lights, and residential point density but not demographic data. The entropy method was used to construct the spatial data [37]. In addition, gross domestic product (GDP) was also used to achieve spatialization [38]. The data on the distribution of nationalities were obtained from the statistical material of the National Ethnic Affairs Commis- 
sion of the People's Republic of China. Data on the Wenchuan earthquake were collected from the Evaluation Report of the Range of the Wenchuan Earthquake Disaster.

\subsection{Methods}

The Landsat TM/ETM images have the same bands and strips, with imaging times occurring between June and September. Images taken during this period have relatively few clouds, allowing the surface features to be easily recognized. Band composition, geometric correction, image mosaic, clipping, and supervised classification functions were performed in ENVI 5.3. The coordinate system of the processed images was unified into GCS_WGS_1984. According to the classified standard of land utilization status (GB/T 21010-2017), the processed images were divided into nine categories: cultivated land, forestland, grassland, shrubland, wetland, water, tundra, construction land, and bare land. For supervised classification, the extraction of the spatial distribution of land utilization was based on support vector machine classification and man-machine interactive land resource remote sensing interpretation. The images were subsequently manipulated with cluster analysis and filtering to obtain five LUCC periods. The construction of the land utilization transfer matrix was based on the LUCC and performed in ArcGIS software (The manufacturer is GeoScene Information Technology Co., Ltd. The software has been sourced in Guangzhou, China).

Habitat quality can reflect biodiversity in the landscape and survival suitability for flagship species. The natural breaks function in ArcGIS was used to divide the habitat quality data into 5 classes (lowest habitat quality $(L L)=(0,0.2)$, middle-low habitat quality $(\mathrm{LH})=(0.2,0.6)$, middle habitat quality $(\mathrm{M})=(0.6,0.7)$, middle-high habitat quality $(\mathrm{HL})=(0.7,0.9)$, and highest habitat quality $(\mathrm{HH}=(0.9,1))$ to analyse the spatial and temporal differences in habitat quality.

\section{- Ecological Niche Evaluation Model}

According to the ecological niche evaluation model and the characteristics of the giant panda habitat, an ecological niche comprehensive evaluation index system was constructed for giant panda habitat, which included 4 dimensions and 18 measurement indicators. The dimensions include giant panda habitat levels, support force levels of giant panda habitat, bound levels of the natural environment, and bound levels of the social economy (as shown in Table 1).

\section{- Ecological niche width level calculation for giant panda habitat}

We first conducted the data standardization to nondimensionalise the measurement indicators to unify their units and dimensions using formula:

$$
X_{i j}=\left|x_{i j}-\overline{x_{j}} / \delta_{j}\right|,
$$

In Formula (1), $X_{i j}$ and $x_{i j}$ are the standardized value and original value of indicator $j$ in region $i$, respectively, and $\overline{x_{j}}$ and $\delta_{j}$ are the arithmetic mean and standard deviation, respectively $[39,40]$.

The formulas for the weight calculation were

$$
\begin{gathered}
V=\delta_{j} / \overline{x_{j}} \\
W_{j}=V / \sum_{j=1}^{n} V_{j}
\end{gathered}
$$

In Formula (2), $V$ is the variable coefficient of each indicator. In Formula (3), $W_{j}$ is the weight of indicator $j[39,40]$.

The formula for the calculation of ecological niche width was

$$
N_{i}=W_{i k}\left(S_{i}+A_{i} P_{i}\right) / \Sigma_{j=1}^{n}\left(S_{i}+A_{i} P_{i}\right)
$$


Table 1. Ecological niche comprehensive evaluation index system of giant panda habitat.

\begin{tabular}{|c|c|c|}
\hline Ecological Niche Dimensions & Measurement Indicators & Meaning of Indicators \\
\hline$X_{1}$ : Giant panda habitat levels & $\begin{array}{l}x 1 \text { : Density of wild giant panda population } \\
x 2 \text { : Percentage of giant panda habitat area } \\
x 3 \text { : Congestion degree of giant panda habitat } \\
x 4 \text { : Connectivity of giant panda habitat }\end{array}$ & $\begin{aligned} & x 1=P_{G} / S_{R} \\
& x 2=S_{H} / S_{R} \\
& x 3=S_{H} / P_{G} \\
& 0=\text { No, } 1=\text { Contiguous to other habitats }\end{aligned}$ \\
\hline $\begin{array}{l}X_{2} \text { : Support force levels of giant } \\
\text { panda habitat }\end{array}$ & $\begin{array}{c}x 5 \text { : Forest coverage } \\
x 6: \text { Biodiversity index } \\
x 7: \text { Percentage of advantageous aspect } \\
\text { (eastern and southern aspect) } \\
x 8 \text { : Percentage of advantageous slope }\left(6-30^{\circ}\right)\end{array}$ & $\begin{array}{c}x 5=S_{F} / S_{R} \\
x 6=0.2 R_{V}+0.2 R_{P}+0.2 D_{E}+0.2 E_{D}+0.1 R_{T}+ \\
0.1\left(100-E_{I}\right) \\
x 7=S_{A} / S_{R} \\
x 8=S_{S} / S_{R}\end{array}$ \\
\hline $\begin{array}{l}X_{3}: \text { Bound levels of the } \\
\text { natural environment }\end{array}$ & $\begin{array}{c}x 9: \text { Temperature } \\
x 10: \text { Amount of precipitation } \\
x 11 \text { : Earthquake zone }\end{array}$ & $\begin{array}{c}- \\
- \\
0=\text { No, } 1=\text { Low severity, } 2=\text { More severe, } \\
3=\text { Most severe }\end{array}$ \\
\hline $\begin{array}{l}X_{4}: \text { Bound levels of the } \\
\text { social economy }\end{array}$ & $\begin{array}{c}x 12 \text { : Density of population } \\
x 13 \text { : Minority prevalence } \\
x 14: \text { Vast area of extreme poverty } \\
x 15: \text { Percentage of construction land } \\
x 16: \text { Percentage of cultivated land } \\
x 17 \text { : Road density } \\
x 18 \text { : Proportion of tourist quantity }\end{array}$ & $\begin{array}{c}x 12=P / S_{R} \\
0=\mathrm{No}, 1=1 \text { Minority, } 2=2 \text { Minority } \\
\text { populations, } 3=3 \text { Minority populations } \\
0=\mathrm{No}, 1=\text { Yes } \\
x 15=\mathrm{S}_{\mathrm{CO}} / S_{R} \\
x 16=\mathrm{S}_{\mathrm{CU}} / S_{R} \\
x 17=L_{R} / S_{R} \\
x 18=\mathrm{GDP} / S_{R}\end{array}$ \\
\hline
\end{tabular}

Notes: $\mathrm{PG}=$ wild giant panda population; $\mathrm{SH}=$ giant panda habitat area; $\mathrm{SR}=$ area of region; $\mathrm{SF}=$ forestland area; $\mathrm{RV}=$ normalized wildlife abundance; $\mathrm{RP}=$ normalized wild vascular plant abundance; $\mathrm{DE}=$ normalized diversity of ecosystem types; $\mathrm{ED}=$ normalized species diversity; RT = normalized threatened species abundance; $\mathrm{EI}=$ normalized invasiveness of alien species; $\mathrm{SA}=$ area of advantageous aspect; $\mathrm{SS}=$ area of advantageous slope; $\mathrm{P}=$ population; $\mathrm{SCO}=$ construction land area; $\mathrm{SCU}=$ cultivated land area; $\mathrm{LR}=$ road mileage.

In Formula (4), $i, j=1,2, \ldots, n ; N_{i}$ is the relative ecological niche of region $i ; S_{i}$ and $S_{j}$ are the states in regions $i$ and $j$, respectively; $P_{i}$ and $P_{j}$ are the potentials in regions $i$ and $j$, respectively; $A_{i}$ and $A_{j}$ are dimensional conversion coefficients; $S_{i}+A_{i} P_{i}$ is the absolute ecological niche of region $i$; and $W_{i k}$ is the weight of $k$ in region $i$. The ecological niche width ranges from 0 to 1 . When the width is closer to 1 , the region has a relatively high ecological suitability $[39,40]$.

The comprehensive ecological niche width was obtained on the basis of the relative ecological niche width through the calculation of the arithmetic mean according to the formula

$$
M_{i}=\sum_{j=1}^{n} N_{i j} w_{j}
$$

In Formula (5), $M_{i}$ is the comprehensive ecological niche width of region $i, N_{i j}$ is the relative ecological niche width of dimension $j$, and $W_{j}$ is the weight of dimension $j[39,40]$.

Ecological niche overlap, which is used to reflect ecological competition, uses the formula:

$$
O_{j k}=\sum_{i=1}^{n} P_{i j} P_{i k} /\left(\sum_{i=1}^{n} P_{i j}^{2} \sum_{i=1}^{n} P_{i k}^{2}\right)^{1 / 2}
$$

In Formula (6), $O_{j k}$ is the value of ecological niche overlap between $k$ and $j, n$ is the total resource value, and $P_{i j}$ and $P_{i k}$ are the proportions of $k$ and $j$ in the total resources in region $i$, respectively $[39,40]$.

\section{Results}

\subsection{Dynamic Changes in Landscape Pattern}

The rapid development of the social economy has driven great changes in the landscape patterns of Sichuan giant panda distribution areas over the past two decades. To analyse the changes in landscape structure in giant panda distribution areas in Sichuan Province, the area of land-use types and area ratio of land-use types in 1995 and 2015 
were calculated. The area of forestland decreased by $1.73 \%$. Furthermore, the areas of construction land and unused land increased by $48.15 \%$ and $1.62 \%$, respectively (Table 2 ).

Table 2. Land-use transfer matrix of counties in giant panda distribution areas in Sichuan Province between 1995 and 2015.

\begin{tabular}{|c|c|c|c|c|c|c|c|c|c|c|c|c|c|c|}
\hline & \multirow{3}{*}{ Land-Use Type } & \multicolumn{13}{|c|}{1995} \\
\hline & & \multicolumn{2}{|c|}{ Cultivated Land } & \multicolumn{2}{|c|}{ Forestland } & \multicolumn{2}{|c|}{ Grassland } & \multicolumn{2}{|c|}{ Water } & \multicolumn{2}{|c|}{ Construction Land } & \multicolumn{2}{|c|}{ Unused Land } & \multirow{2}{*}{$\begin{array}{c}\text { Transfer in } \\
\begin{array}{c}\text { Area } \\
\left(\mathrm{km}^{2}\right)\end{array}\end{array}$} \\
\hline & & $\begin{array}{c}\text { Area } \\
\left(\mathrm{km}^{2}\right)\end{array}$ & $\begin{array}{c}\text { Ratio } \\
(\%)\end{array}$ & $\begin{array}{c}\text { Area } \\
\left(\mathrm{km}^{2}\right)\end{array}$ & $\begin{array}{l}\text { Ratio } \\
(\%)\end{array}$ & $\begin{array}{c}\text { Area } \\
\left(\mathrm{km}^{2}\right)\end{array}$ & $\begin{array}{l}\text { Ratio } \\
(\%)\end{array}$ & $\begin{array}{c}\text { Area } \\
\left(\mathrm{km}^{2}\right)\end{array}$ & $\begin{array}{c}\text { Ratio } \\
(\%)\end{array}$ & $\begin{array}{c}\text { Area } \\
\left(\mathrm{km}^{2}\right)\end{array}$ & $\begin{array}{c}\text { Ratio } \\
(\%)\end{array}$ & $\begin{array}{c}\text { Area } \\
\left(\mathrm{km}^{2}\right)\end{array}$ & $\begin{array}{c}\text { Ratio } \\
(\%)\end{array}$ & \\
\hline \multirow{7}{*}{2015} & Cultivated land & $12,872.47$ & 98.43 & 167.98 & 1.28 & 25.47 & 0.19 & 1.46 & 0.01 & 9.85 & 0.08 & 0 & 0 & $13,077.22$ \\
\hline & Forestland & 140.37 & 0.27 & $50,914.20$ & 98.79 & 478.02 & 0.93 & 0.65 & 0.00 & 0.76 & 0.00 & 2.06 & 0.00 & $51,536.06$ \\
\hline & Grassland & 115.40 & 0.24 & 1252.04 & 2.64 & $45,967.48$ & 96.99 & 2.37 & 0.01 & 0.12 & 0.00 & 58.96 & 0.12 & $47,396.47$ \\
\hline & Water & 90.28 & 10.37 & 14.65 & 1.68 & 37.20 & 4.27 & 722.87 & 83.06 & 5.26 & 0.60 & 0 & 0 & 870.26 \\
\hline & Construction land & 164.25 & 26.95 & 29.98 & 4.92 & 17.35 & 2.85 & 0.55 & 0.09 & 395.41 & 64.87 & 2.00 & 0.33 & 609.52 \\
\hline & Unused land & 4.04 & 0.09 & 65.74 & 1.50 & 62.95 & 1.44 & 0 & 0 & 0.03 & 0.00 & 4240.65 & 96.96 & 4373.41 \\
\hline & Transfer out & $13,386.81$ & & $52,444.57$ & & $46,588.46$ & & 727.90 & & 411.44 & & 4303.67 & & $117,862.93$ \\
\hline
\end{tabular}

When only the giant panda nature reserves are considered, the area of core habitat decreased between 1995 and 2015. However, the area of construction land increased by 1.62 times during this period, and $61.15 \%$ of the forestland transitioned to construction land (Table 3).

In 1995, there were concentrated continuous forestland in Kangding, Pingwu, Jiulong, etc. In 2015, there were concentrated continuous forestland in Pingwu, Beichuan, Songpan, etc. The decreases in forestland mainly occurred in Pingwu, Anzhou, Wenchuan, etc., between 1995 and 2015. The main cause of these changes was that human resource-utilization activities seriously damaged the vegetation, which exacerbated the fragmentation of the landscape. Although the area of forestland rapidly increased under the support of several forestry projects over the past two decades, the area of natural forest declined during this period. One possible reason for this observation is that the customs of household resource utilization and strong resource dependency led to the degeneration of natural forests. In general, the regional area of forestland showed a growth trend over the past two decades, which indicates the remarkable effect of the conservation of natural resources in the Sichuan giant panda distribution area.

Dynamic changes in habitat quality reflect the conflict between human resourceutilization behaviour and habitat resource protection [41]. The giant panda is a flagship species in biodiversity conservation [29]. However, human activities have destroyed the habitat of this species, and the distribution of giant pandas sharply decreased. When household livelihood activities lack space for expansion, humans cut down forestland and transform grassland, increasing the area of cultivated land and construction land for their survival [42]. However, these behaviours lead to the shrinking and fragmentation of giant panda habitats, which could threaten the survival of this species.

Table 3. Land-use transfer matrix of giant panda nature reserves in Sichuan Province between 1995 and 2015.

\begin{tabular}{|c|c|c|c|c|c|c|c|c|c|c|c|c|c|c|}
\hline & \multirow{3}{*}{ Land-Use Type } & \multicolumn{13}{|c|}{1995} \\
\hline & & \multicolumn{2}{|c|}{ Cultivated Land } & \multicolumn{2}{|c|}{ Forestland } & \multicolumn{2}{|c|}{ Grassland } & \multicolumn{2}{|c|}{ Water } & \multicolumn{2}{|c|}{ Construction Land } & \multicolumn{2}{|c|}{ Unused Land } & \multirow{2}{*}{$\begin{array}{c}\text { Transfer in } \\
\begin{array}{c}\text { Area } \\
\left(\mathrm{km}^{2}\right)\end{array}\end{array}$} \\
\hline & & $\begin{array}{c}\text { Area } \\
\left(\mathrm{km}^{2}\right)\end{array}$ & $\begin{array}{c}\text { Ratio } \\
(\%)\end{array}$ & $\begin{array}{c}\text { Area } \\
\left(\mathrm{km}^{2}\right)\end{array}$ & $\begin{array}{l}\text { Ratio } \\
(\%)\end{array}$ & $\begin{array}{c}\text { Area } \\
\left(\mathrm{km}^{2}\right)\end{array}$ & $\begin{array}{l}\text { Ratio } \\
(\%)\end{array}$ & $\begin{array}{c}\text { Area } \\
\left(\mathrm{km}^{2}\right)\end{array}$ & $\begin{array}{c}\text { Ratio } \\
(\%)\end{array}$ & $\begin{array}{c}\text { Area } \\
\left(\mathrm{km}^{2}\right)\end{array}$ & $\begin{array}{l}\text { Ratio } \\
(\%)\end{array}$ & $\begin{array}{c}\text { Area } \\
\left(\mathrm{km}^{2}\right)\end{array}$ & $\begin{array}{l}\text { Ratio } \\
(\%)\end{array}$ & \\
\hline \multirow{7}{*}{2015} & Cultivated land & 241.70 & 97.52 & 5.76 & 2.32 & 0.39 & 0.16 & 0 & 0 & 0 & 0 & 0 & 0 & 247.84 \\
\hline & Forestland & 7.81 & 0.07 & $10,901.31$ & 98.83 & 120.96 & 1.10 & 0.42 & 0.00 & 0.03 & 0.00 & 0 & 0 & $11,030.53$ \\
\hline & Grassland & 18.08 & 0.16 & 520.57 & 4.59 & $10,799.99$ & 95.23 & 0.62 & 0.01 & 0 & 0 & 1.56 & 0.01 & $11,340.83$ \\
\hline & Water & 0 & 0 & 0.74 & 0.24 & 0.11 & 0.04 & 308.22 & 99.73 & 0 & 0 & 0 & 0 & 309.06 \\
\hline & Construction land & 0.09 & 0.98 & 5.46 & 61.15 & 0 & 0 & 0 & 0 & 3.38 & 37.87 & 0 & 0 & 8.92 \\
\hline & Unused land & 0.81 & 0.08 & 34.20 & 3.48 & 1.09 & 0.11 & 0 & 0 & 0 & 0 & 946.26 & 96.33 & 982.36 \\
\hline & Transfer out & 268.49 & & $11,468.03$ & & $10,922.54$ & & 309.26 & & 3.41 & & 947.82 & & $23,919.54$ \\
\hline
\end{tabular}

In the Sichuan giant panda distribution areas, the areas of highest habitat quality $(\mathrm{HH})$ and lowest habitat quality (LL) decreased by $1.73 \%$ and increased by $5.68 \%$, respectively, between 1995 and 2015 (as shown as Figure 1B), and these changes always occurred on forest edges and along roadways (as shown as Figure 2). The areas of middle-high habitat quality (HL) and $\mathrm{M}$ increased by $1.73 \%$ and $19.56 \%$, respectively (as shown in Figure 1B). Areas of middle-low habitat quality (LH) decreased by $2.31 \%$ (as shown in Figure 1B). In general, the areas of middle-high habitat quality (HL) and middle habitat quality (M) increased in the study area. 
These results demonstrate that the Returning Farmland into Forest (RFIF) programme and the Natural Forest Protection Project (NFPP) have achieved remarkable results over the past 20 years $[43,44]$ and that the ecological environment of the Sichuan giant panda distribution areas has been greatly improved [45].

To visualize the conversion between different habitat types, maps of habitat-type conversion were generated based on a land-use change matrix (as shown in Figure 2). The highest habitat quality $(\mathrm{HH})$ and middle-high habitat quality (HL) areas shifted to lowest habitat quality (LL) areas in the surroundings of communities and on roadsides. This pattern mainly occurred in the communities surrounding nature reserves, such as Baozuo, Xiaohegou, Piankou, etc., as well as within nature reserves, such as Qianfoshan, Longxi-Hongkou, Wolong, etc. In addition, the highest habitat quality $(\mathrm{HH})$ and middlehigh habitat quality (HL) areas shifted to middle-low habitat quality (LH) areas where high-intensity agricultural resource-utilization activities occurred, typically within the Xuebaoding Nature Reserve and surrounding communities and within the Wolong Nature Reserve. With the development of ecological tourism, $\mathrm{M}$ areas shifted to middle-low habitat quality (LH) and lowest habitat quality (LL) areas in the communities surrounding nature reserves, such as Tangjiahe and Labahe. In recent years, the control and guidance of the resource-utilization behaviour of farmers has been strengthened. Therefore, the lowest habitat quality (LL) and middle-low habitat quality (LH) areas shifted to middlehigh habitat quality (HL) and highest habitat quality $(\mathrm{HH})$ areas in the region of the Yele Nature Reserve.

\subsection{Ecological Niche Evaluation}

For giant panda habitat levels, the relative ecological niche widths of the Sichuan giant panda distribution areas in 2015 were generally higher than those in 1995 (as shown in Figure 3). The main reason for this observation is that giant panda conservation projects drove the restoration and expansion of suitable habitat for this species and the growth of the wild giant panda population $[46,47]$. The main giant panda conservation efforts included the giant panda protection system, protection schemes (e.g., migration from the core of nature reserves, community co-management, and a transition in resourceutilization behaviour) and multiple sources of support (e.g., the Chinese government, international organizations, non-governmental organizations, and the community of caring people) [48]. Thus, the relative ecological niche width of the giant panda habitat in the Sichuan distribution areas significantly increased between 1995 and 2015. In this region, the relative ecological niche widths were higher than 0.05 in Baoxing, Wenchuan, Pingwu, and Beichuan.

According to the Master Plan of the Chinese Giant Panda National Park, $92.80 \%$ of the land area in Baoxing is considered part of the Giant Panda National Park $\left(2889 \mathrm{~km}^{2}\right)$. A total of $68.50 \%$ of the land area in Wenchuan is also considered part of the Giant Panda National Park $\left(2794 \mathrm{~km}^{2}\right)$. The area of the Giant Panda National Park in Pingwu is the largest in Sichuan Province, with an area of $3398 \mathrm{~km}^{2}$. In Beichuan, an area of $1059 \mathrm{~km}^{2}$ is considered part of the Giant Panda National Park, representing 36.90\% of the land area. The above information indicates that these areas occupy a dominant position in the habitat system of the giant panda in Sichuan Province and reveals that giant panda habitat has been effectively protected over the past 20 years.

In terms of the support force levels of giant pandas, the relative ecological niche widths of the Sichuan giant panda distribution areas in 2015 were slightly higher than those in 1995 (as shown in Figure 3). The main reason for this result is that Chinese forestry projects (Returning Farmland into Forest (RFIF), the Natural Forest Protection Project (NFPP), and Ecological Public Welfare Forest Construction (EPWFC) have led to a significant increase in forest coverage in the giant panda distribution area, and the primary habitat of the giant panda and other species has gradually recovered $[44,46,49]$. Furthermore, the continually improving giant panda conservation system and technology have also promoted an increase in giant panda abundance and sympatric speciation and 
also increased the area of advantageous habitat (eastern and southern aspects, $6-30^{\circ}$ slope). As a result, the support force levels of giant pandas have increased.

In terms of the bound levels of the natural environment, the relative ecological niche widths of the Sichuan giant panda distribution areas in 2015 were significantly higher than those in 1995 (as shown in Figure 3). The main reason for this result is that the Sichuan giant panda distribution areas also experienced temperature and precipitation changes under the background of global climate warming [50,51]. In addition, most habitats overlap with earthquake zones. Thus, climate and crustal movement have constrained the quality of giant panda habitat.

The bound levels of the social economy in 2015 were generally higher than those in 1995 (as shown in Figure 3). There are four main reasons for this result. First, the rapid increase in population has caused the pressure on natural resources to rise $[4,52]$. Second, there is a contradiction between the preservation of multi-ethnic customs and ecological protection [53]. Third, access to farmer livelihood resources conflicts with the thinking regarding resource-utilization constraints [54]. Last, the booming regional economy (causing such effects as the extension of the area of construction and cultivated land, an increase in road density, and growth of the GDP) has compressed the space available for primary habitat, resulting in a continuous increase in the bound levels of the social economy in giant panda distribution areas over the past 20 years [4].

According to Figure 4, the ecological niche overlap in the giant panda distribution areas in 2015 was generally lower than that in 1995. There are two main reasons for this result. On the one hand, the prosperity of modern economic sectors (industry and services) attracted a greater labour force from giant panda distribution areas for employment, which reduced the resource dependence of farmers and the competition for internal resources [55]. On the other hand, giant panda conservation efforts not only focused on growth in the number of giant pandas and the area of their habitat but also addressed alleviation of the contradiction between protection and development to solve the survival predicament of farmers in the study area $[4,54]$. Therefore, governments have altered the livelihood structure and resource-utilization preferences of regional farmers through community co-management, energy revolution, and nature education. The competition for internal resources decreased under these measures, and protection and development have been in equilibrium.

\subsection{Effects of Different Driving Factors on Giant Panda Habitat}

The factors driving giant panda habitat changes include abiotic factors, biotic factors, and disturbance from human resource-utilization behaviour [56].

\section{- $\quad$ Abiotic factors}

Giant panda habitat is mainly restricted by abiotic factors, including the congestion degree [20], connectivity [57], aspect [58], slope [59], temperature [60], precipitation [61], and status as an earthquake zone [62,63].

The congestion degree of giant panda habitat is the suitable living density of giant pandas. According to research on the activity range of giant pandas in the Wolong Nature Reserve, the suitable activity area of a giant panda is approximately $5 \mathrm{~km}^{2}$ [64]. When the density of giant pandas exceeds the density that can be supported on the basis of the suitable activity area, competition will intensify [65]. The relative ecological niche widths in the giant panda habitat levels have increased dramatically over the past two decades. One of the main reasons for this result is the expanded area of giant panda habitat and reduced congestion degree. Furthermore, conservation concepts have also changed during this period. The contradiction between conservation and development has been in remission. With the decrease in interference from the community, the area of giant panda habitat has expanded, and marginal habitats can now be used by giant pandas. Therefore, the relief of congestion degree helps to increase relative ecological niche widths in the giant panda habitat levels. 


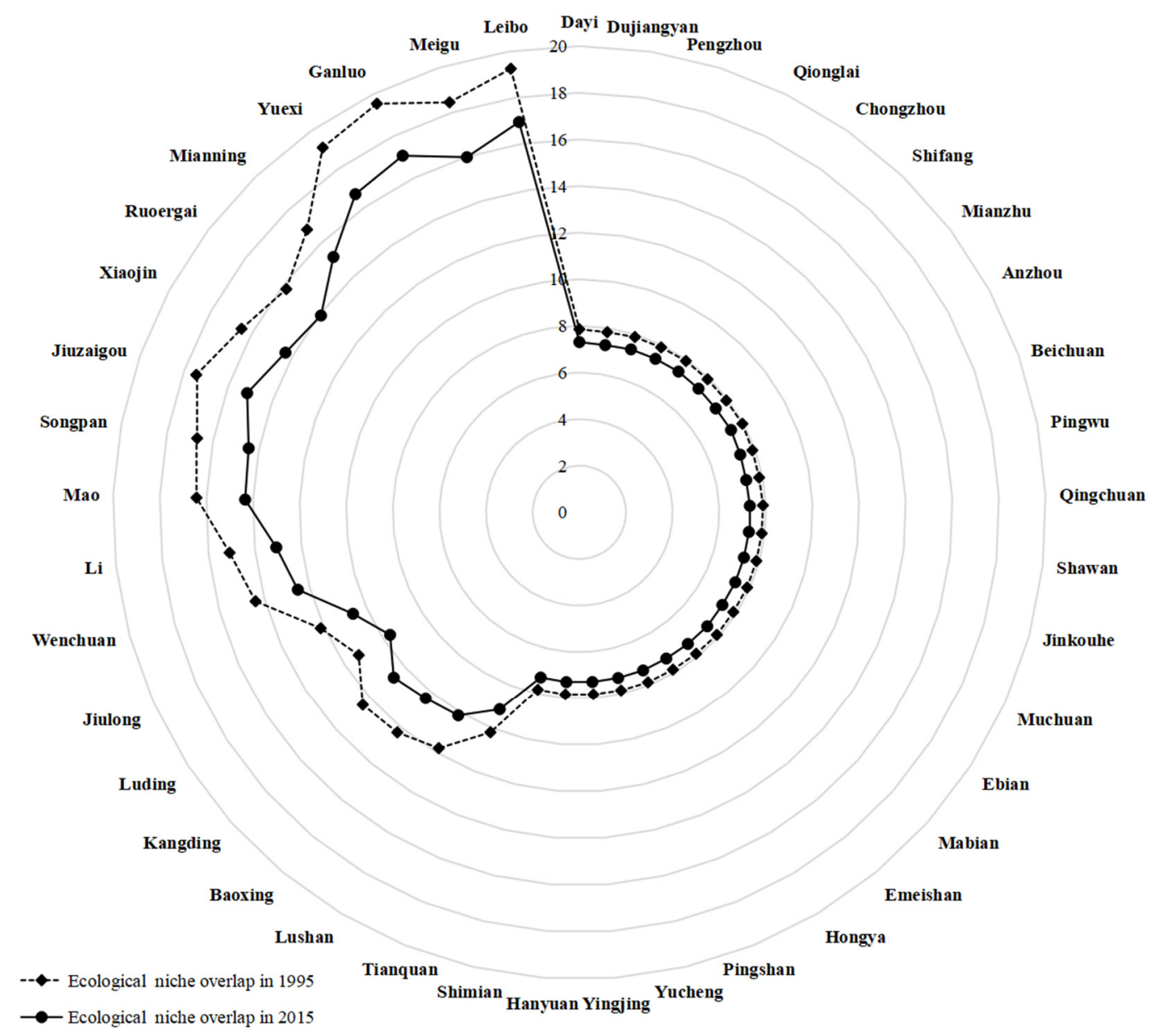

Figure 4. Ecological niche overlap in giant panda distribution areas in Sichuan Province in 1995 and 2015. Note: (1) The ecological niche overlap in Sichuan giant panda distribution areas in 2015 is generally higher than that in 1995. (2) The areas with large differences in overlap between 1995 and 2015 are distributed in the western and southern Sichuan giant panda distribution areas, such as Leibo, Meigu, Ganluo, Yuexi, Mianning, Ruoergai, Xiaojin, Jiuzaigou, Songpan, Mao, Li, Wenchuan, Jiulong, Kangding, Baoxing, Lushan, and Tianquan.

Connectivity of the habitat is used to measure the isolation of giant panda habitats. Habitat fragmentation has occurred for a long time in giant panda distribution areas, and human activities are the main cause of this fragmentation [66]. With the intensification of human interference, giant pandas have become isolated in numerous subpopulations, experiencing habitat changes and limited gene flow between different subpopulations [67]. We found that the connectivity in 2015 was better than that in 1995. Under this background, population isolation has been continually addressed, and reproduction in this species has been guaranteed. Moreover, there will be more opportunities for giant pandas to exchange genes with the establishment of national parks, and connectivity will effectively increase, resulting in an improvement in relative ecological niche widths.

Regarding the aspect of the habitats, Wei et al. (1996) found that giant pandas mostly choose eastern aspects $\left(45-135^{\circ}\right)$ and southern aspects $\left(135-225^{\circ}\right)$ for habitat [68]. The eastern and southern slopes are relatively warm, while the western and northern slopes are relatively cold and dry. As a result of ecological migration, residences have moved out from the core and buffer zones of nature reserves during the past two decades, following which the areas of advantageous aspect have increased, which has also driven the improvement of relative ecological niche widths.

Regarding the slope, Zhou (2007) found that giant pandas frequently use slopes of $6-30^{\circ}$ for habitat and less often use higher slopes [64]. With the intensification of regulatory 
regimes in nature reserves, some giant pandas are increasing their utilization of low slopes. Over the past two decades, the giant panda encounter rate has increased significantly, indicating that the giant panda habitat crisis has eased. The improvement of habitat drives the increase in relative ecological niche widths with the intensification of regulatory regimes in nature reserves.

Under the background of global climate change, the temperature in these areas was significantly higher in 2015 than in 1995, and the precipitation was significantly lower in 2015 than in 1995. In addition, these areas have seen an increase in low-altitude and medium-density river system areas under this climate background [68]. Giant pandas prefer warm and wet conditions [69]. The range of suitable habitats continues along rivers, expanding the activity space and reducing intraspecific competition, which drives the improvement of relative ecological niche widths [64,70].

Sichuan giant panda distribution areas are highly coincident with earthquake zones. Some areas were badly affected by the Wenchuan earthquake (2008), including Wenchuan, Beichuan, Qingchuan, Anzhou, and Dujiangyan. The Wenchuan earthquake destroyed the staple food of pandas, bamboo [71], while large areas of forest were lost and deteriorated [72]. These disasters have threatened food safety and habitat of giant pandas [73]. Moreover, genetic diversity was reduced, and habitat fragmentation was accelerated. However, the Wenchuan earthquake represents a major turning point in the development of giant panda conservation. During post-quake reconstruction, the conservation system of giant pandas was upgraded. The ecological economy has been booming in the Sichuan giant panda distribution areas. To some degree, community co-management has reduced the contradiction between natural reserves and neighbouring communities and has increased protection awareness among the people living there. As a consequence of enhanced conservation, the relative ecological niche widths in the bound levels of the natural environment in 2015 could be greater than those in 1995.

\section{- Biotic factors}

Giant panda habitat is also affected by biotic factors, such as forest coverage [44], biodiversity [74], and variation in habitat areas [55].

Research shows that giant pandas mainly inhabit coniferous, mixed broadleaf-coniferous and broad-leaved forest. They use non-forest habitat types less, such as brushwood, meadow, cropland, and other land types [5-8,75]. Therefore, forest represents the core habitat of giant pandas. High forest coverage is associated with better habitat suitability for giant pandas [43]. With the advancement of forestry projects in China, forest coverage has increased significantly in the Sichuan giant panda distribution areas [4]. Data show that the level of forest coverage in 2015 was higher than that in 1995 (as shown in Figure 5A). With forestry protects driving the optimization of giant panda habitat, the relative ecological niche widths in the support force levels of giant pandas in 2015 could be greater than those in 1995.

Biodiversity indices are important in the evaluation of giant panda habitat [45]. The conservation of giant pandas also protects sympatric species [76]. When protection of the giant panda increases, the abundance of sympatric species also increases [5-8]. In comparison to 1995, the biodiversity in the Sichuan giant panda distribution areas increased significantly in 2015 (Figure 5B). With giant panda conservation driving the optimization of habitat, the relative ecological niche widths in the support force levels of giant pandas in 2015 were greater than those in 1995.

The variation in habitat areas also has an important influence on the quality of giant panda habitat [55]. The data show that the patterns of the variation in habitat areas showed general trends of decreasing/stable forestland area, increasing/stable grassland area, continuously increasing water area (Figure 6), continuously decreasing cultivated land, increasing construction land, and increasing/decreasing unused land (Figure 7). There are two main reasons for these patterns. First, the implementation of major forestry projects stabilized the forestland area after 2000, which resulted in relatively stable survival conditions for giant pandas. Second, with the rapid expansion of tourism in giant panda distribution areas after the Wenchuan earthquake, the increasing footprint of human 
activity caused disturbance to the giant panda habitat. Therefore, there is a bidirectional influence on the habitat of this species. On the one hand, the Returning Farmland into Forest project has reduced the disturbance caused by planting to the giant panda habitat, which has expanded the activity areas for this species. On the other hand, ecological tourism projects have caused disturbances to giant panda habitat, which has forced these animals to abandon marginal habitat.
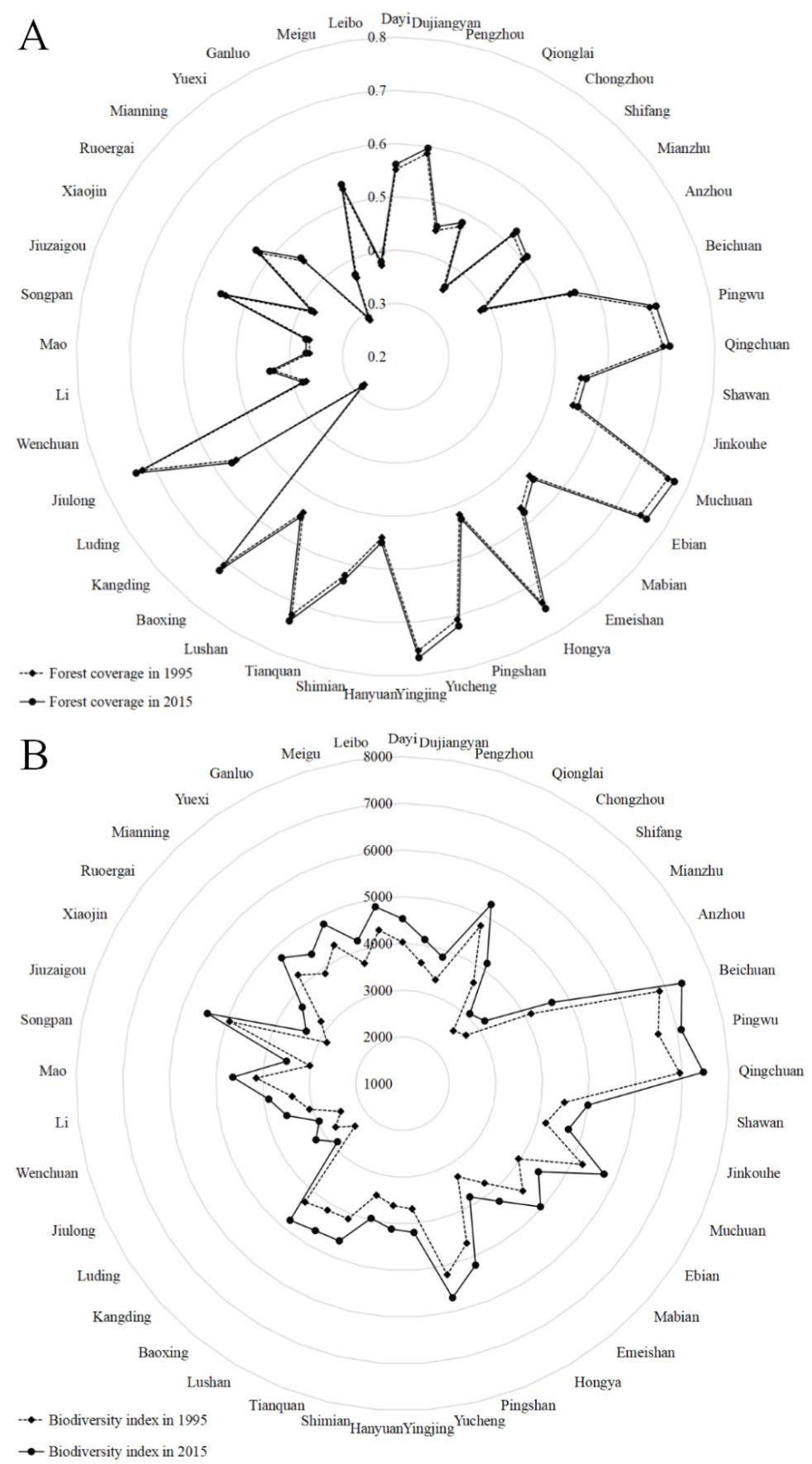

Figure 5. Biotic factors: (A) Forest coverage in giant panda distribution areas in Sichuan Province between 1995 and 2015. (B) Biodiversity of Sichuan giant panda distribution areas between 1995 and 2015. Notes: (1) The forest coverage in Sichuan giant panda distribution areas in 2015 was generally higher than that in 1995. Some counties showed an increase in forest coverage between 1995 and 2015. (2) The biodiversity of Sichuan giant panda distribution areas in 2015 was generally higher than that in 1995. Some counties showed an increase in biodiversity between 1995 and 2015. 

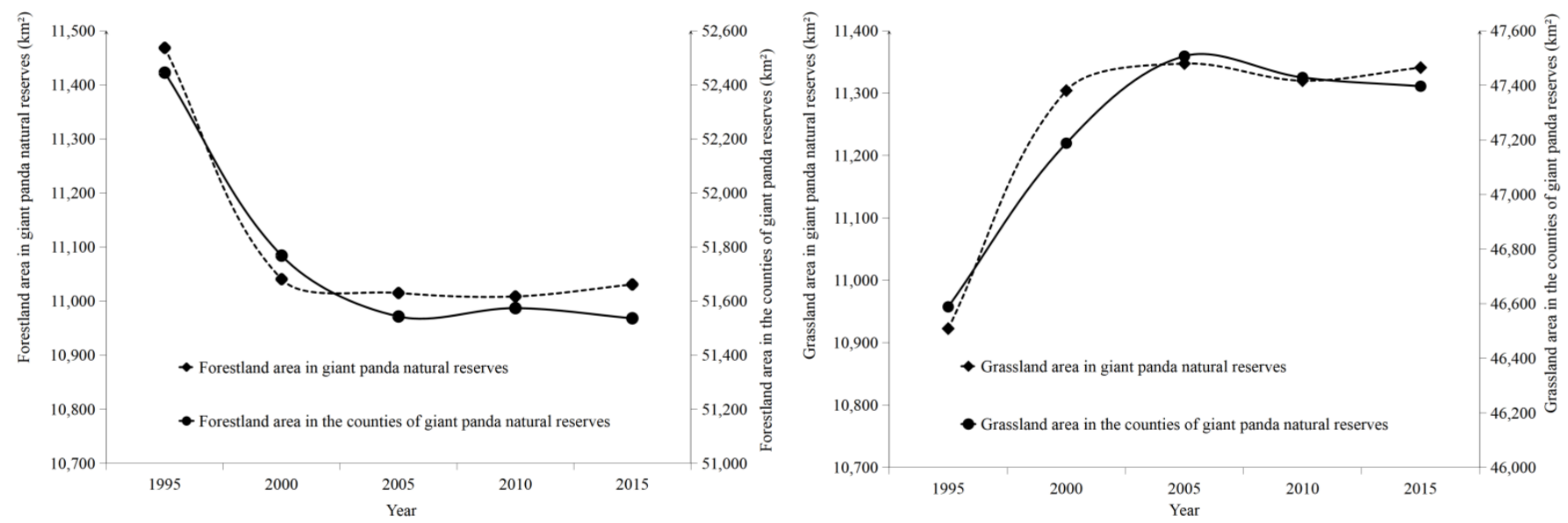

Figure 6. Trends of the changes in habitat landscape area between 1995 and 2015. Note: (1) The trends of the changes in habitat landscape area in the disturbed areas in the giant panda distribution areas between 1995 and 2015 are similar to those in the nature reserves. (2) The forestland area declined between 1995 and 2000. However, the area showed a continuous and unstable rising trend over the past fifteen years. In contrast, the grassland area increased over the past two decades.
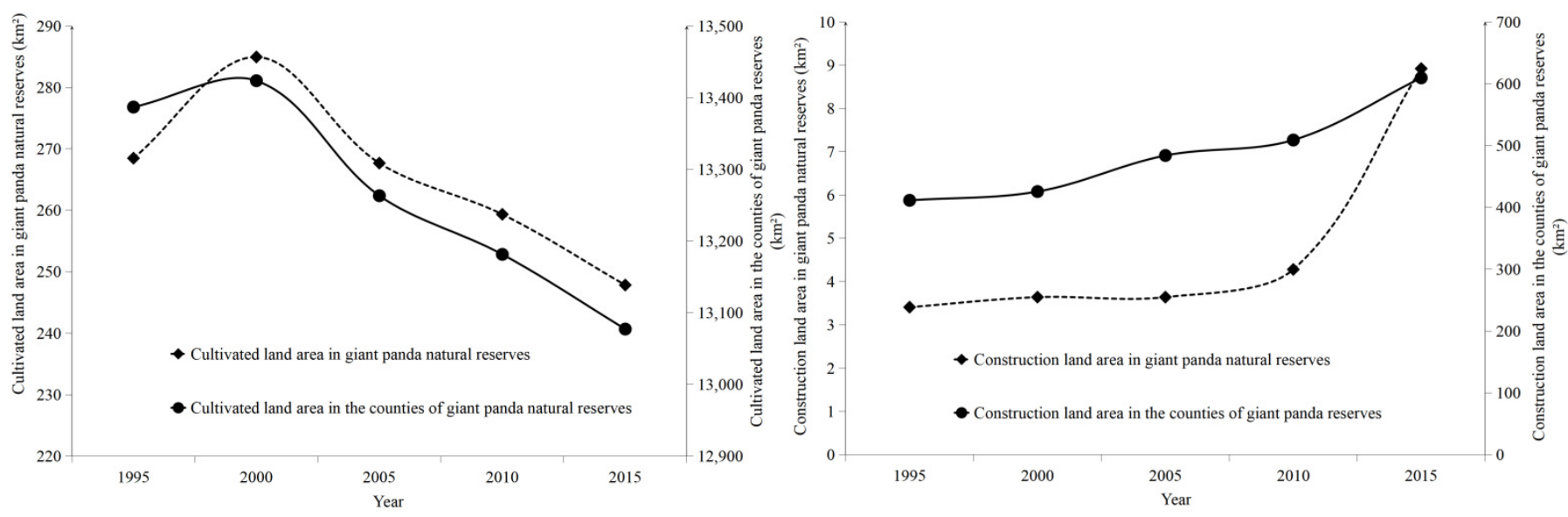

Figure 7. Trends of the change in habitat disturbance area between 1995 and 2015. Note: (1) The trends of the change in habitat disturbance areas in the giant panda distribution areas between 1995 and 2015 are similar to those in the nature reserves. (2) The cultivated land area has declined over the past two decades, while the construction land area has changed little since 1995 .

\section{- $\quad$ Other interference factors}

Giant pandas are mainly distributed in Sichuan Province; minority human populations live in this province, and there are vast areas of extreme poverty. Due to traditional customs, different ethnic groups and poverty-stricken households depend on natural resources, and the production activities of these groups often disturb the giant panda habitat. Therefore, minority populations and poverty are important factors affecting changes in habitat $[77,78]$.

Four minority groups reside in the Sichuan giant panda distribution areas, and they are mainly distributed in 23 counties (Figure 8A). The livelihoods of minority populations always depend on grazing, gathering, and biomass fuel, which represent serious disturbances to giant panda habitat [5-8]. In recent decades, community co-management has limited the resource-utilization behaviour of minority populations in giant panda disturbance areas. Therefore, changes in conservation thought and methods have driven the growth of relative ecological niche widths in the bound levels of the social economy over the past two decades.

Extreme poverty could be an important factor as 19 counties are located in concentrated contiguous extreme poverty areas (Figure 8B). Households in these counties heavily depend on natural resources $[35,54]$. However, the plunder of human resources over the 
past century has thrown delicate ecosystems off balance [79]. Therefore, the contradiction between natural resource conservation and livelihood resource acquisition is apparent in these areas. However, supported by poverty alleviation policy, these land-use conflicts have been alleviated over the past two decades [5-8]. The poverty and ecological problems have been improved, and the relative ecological niche widths in the bound levels of the social economy in 2015 are greater than those in 1995.
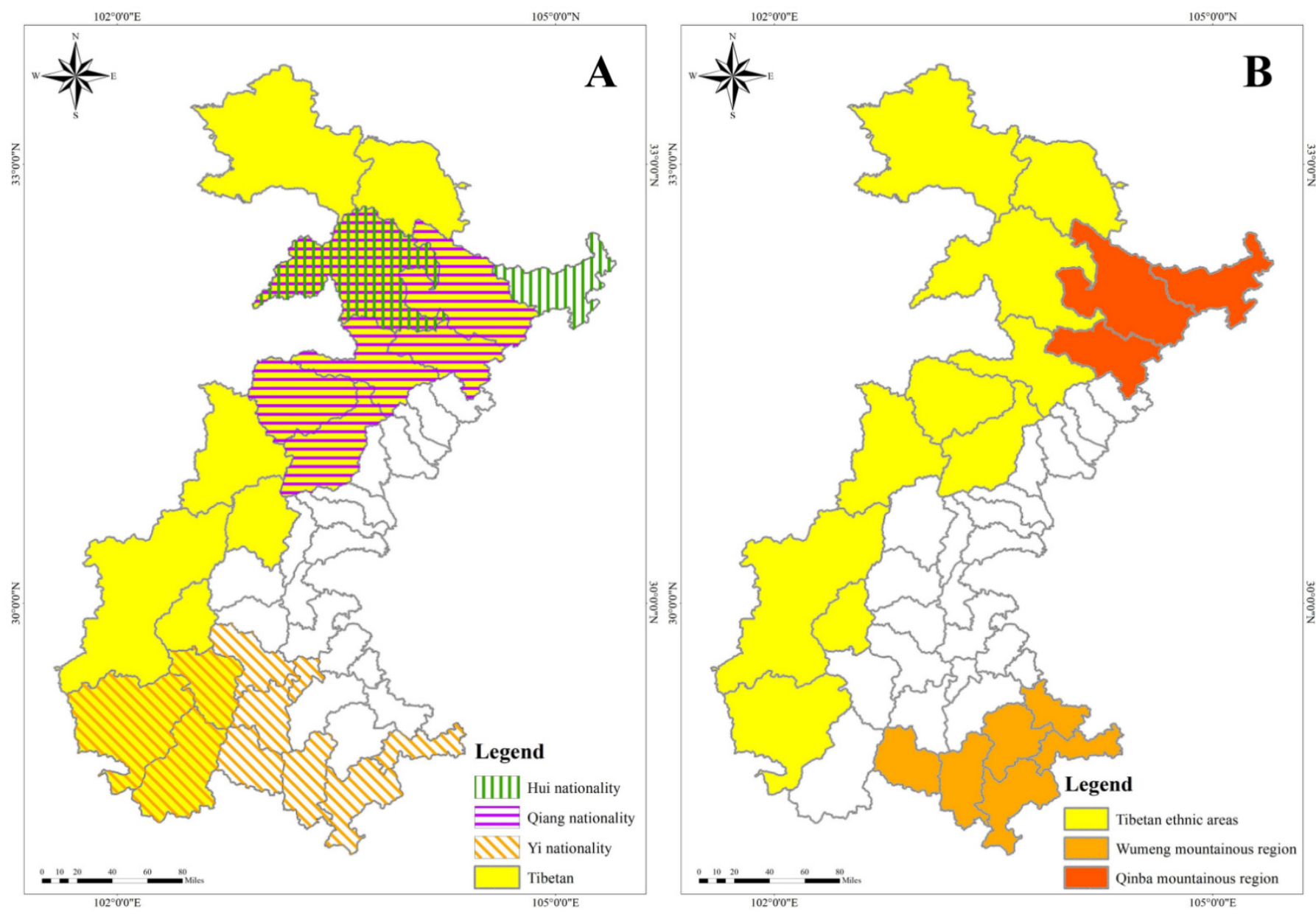

Figure 8. Interference factors: (A) Counties with minority populations in giant panda disturbance areas in Sichuan Province. (B) Counties with areas of extreme poverty in giant panda disturbance areas in Sichuan Province. Notes: (1) The Tibetan people are mainly distributed in the western part of the Sichuan giant panda disturbance areas. People of the Yi nationality are mainly distributed in the southern part of the Sichuan giant panda disturbance areas. People of the Qiang nationality are mainly distributed in the Min Mountains. People of the Hui nationality are mainly distributed in the northern part of the Sichuan giant panda disturbance areas. (2) There are ten multi-nationality counties, which are Qingchuan, Songpan, Beichuan, Pingwu, Wenchuan, Li, Mao, Shimian, Mianning, and Jiulong. (3) Counties with extreme poverty are mainly distributed in the western and southern parts of the Sichuan giant panda disturbance areas. The concentrated contiguous extreme poverty areas include the Tibetan ethnic areas, the Wumeng mountainous region, and the Qinba mountainous region.

\section{Conclusions}

The most direct causes of the variation in giant panda habitat are the changes in land cover and related influencing factors. Although disturbance caused by human activities still exists, the quality of giant panda habitat has still significantly improved as a result of conservation efforts and the revitalization of conservation methods.

From 1995 to 2015, the area of non-forested land decreased significantly and was replaced by increased forestland area, leading the expansion of habitat space in the core of the giant panda disturbance areas, releasing congestion and improving the quality of the 
giant panda habitat. It is interesting that the high-quality land types tended to decrease but the low/middle-quality land types tended to increase. Significant increase in the dominant habitat types drove the effective improvement of giant panda habitat.

Over the past two decades, giant panda conservation projects have promoted changes in conservation thought and management. The coordination of related forestry projects has effectively increased giant panda habitat area and improved dominant habitat. The connectivity of giant panda habitat has also been enhanced. The habitat suitability for the giant panda has been significantly improved.

It must be noted that Chinese giant panda conservation projects focus not only on the reproduction of giant pandas but also on how to alleviate the contradiction between conservation and development and facilitate the coexistence of humans and giant pandas. Community co-management, ecological migration, and poverty alleviation have effectively solved the conflicts associated with resource utilization in multi-ethnic communities, concentrated contiguous extreme poverty areas, and rare species reserves, which also provides a reference for solving similar problems. Such an experience could be very useful to other regions and countries where conflict between conservation and economic utilization is a major challenge.

Chinese giant panda conservation relies on government interference, with governance and management of nature reserves based on administrative division. The levels of conservation in different areas are uneven, and policies have the problem of being onesize-fits-all. Resource utilization behaviours of households in the giant panda disturbance areas have coming into being historically and cannot be reversed overnight. Therefore, determining how to guide households is a long-term process. At present, China is building a giant panda national park, and the institutions and technologies involved in giant panda conservation are being revised.

Author Contributions: Development of the idea, data collection, and writing-original draft preparation, Z.S.; writing - review and editing, Y.L. All authors have read and agreed to the published version of the manuscript.

Funding: This research was funded by the National Natural Science Foundation of China, grant number 71761147003.

Data Availability Statement: The data presented in this study are available on request from the corresponding author.

Acknowledgments: We are thankful for the financial support of the National Natural Science Foundation of China. We express our appreciation to the anonymous referees and editors of the journal for their constructive comments and suggestions.

Conflicts of Interest: The authors declare no conflict of interest.

\section{References}

1. Yu, X.; Hu, D.; Jin, X.; Ge, X.; Yang, L.; Zhao, P.; Zhang, Q. Non-invasive determination of fecal steroid hormones relating to conservation practice in giant panda (Ailuropoda melanoleuca). Anim. Biol. 2011, 61, 335-347.

2. Hu, J. Giant Panda Research; Shanghai Science and Technology Education Press: Shanghai, China, 2001; pp. 1-27.

3. Pan, W. Chances of Survival; Peking University Press: Beijing, China, 2001; pp. 5-12.

4. Qin, Q.; Huang, Y.; Liu, J.; Chen, D.; Zhang, L.; Qiu, J.; Tan, H.; Wen, Y. The landscape patterns of the giant panda protection area in Sichuan Province and Their Impact on Giant Pandas. Sustainability 2019, 11, 5993. [CrossRef]

5. National Forestry Administration. The 3rd National Survey Report on Giant Panda in China; China Science Publishing \& Media Ltd. (CSPM): Beijing, China, 2006; pp. 19-39.

6. Sichuan Provincial Department of Forestry and Grassland. The Pandas of Sichuan. In The 4th Survey Report on Giant Panda in Sichuan Province; Sichuan Science and Technology Publishing House: Chengdu, China, 2015; pp. 1-86.

7. Zhou, L.; Zhang, X.; Jiu, Q. Qinling Giant Panda. In The 4th Survey Report on Giant Panda in Shaanxi Province; Shaanxi Science and Technology Press: Xi'an, China, 2017; pp. 5-13.

8. Shi, Z. The 4th Survey Report on Giant Panda in Gansu Province; Gansu Science and Technology Press: Lanzhou, China, 2017; pp. 15-27.

9. Ministry of Ecology and Environment of the People's Republic of China. China Nature Reserves. Available online: www.mee.gov. cn/ywgz/zrstbh/zrbhdjg/201905/P020190514616282907461.pdf (accessed on 10 October 2021). 
10. Qi, D.; Hu, Y.; Gu, X.; Li, M.; Wei, F. Ecological niche modeling of the sympatric giant and red pandas on a mountain-range scale. Biodivers. Conserv. 2009, 18, 2127-2141. [CrossRef]

11. Li, D.; Wang, X.; Zhao, X.; Zhou, H.; Hong, M.; Wei, W.; Han, H.; Tang, J.; Zhang, Z. The relative role of climate, land-use and spatial structure on spatial distribution pattern of species richness of large and medium mammals sympatric with giant pandas. Acta Theriol. Sin. 2021, 41, 377-387.

12. Luo, L.; Zhou, H.; Tang, J.; Wei, W.; Han, H.; Zhang, Z.; Hong, M. Niche differentiation between giant pandas and its sympatric species in altitude distribution. Acta Theriol. Sin. 2020, 40, 337-345.

13. Han, H.; Wei, W.; Hu, Y.; Nie, Y.; Ji, X.; Yan, L.; Zhang, Z.; Shi, X.; Zhu, L.; Luo, Y.; et al. Diet evolution and habitat contraction of giant pandas via stable isotope analysis. Curr. Biol. 2019, 29, 664-669. [CrossRef] [PubMed]

14. Hull, V.; Roloff, G.; Zhang, J.; Liu, W.; Zhou, S.; Huang, J.; Xu, W.; Ouyang, Z.; Zhang, H.; Liu, J. A synthesis of giant panda habitat selection. Ursus 2014, 25, 148-162. [CrossRef]

15. Zhou, S.; Yang, J.; Wang, L.; Tan, Y.; Huang, J.; Zhang, H.; Wang, P.; Zhou, X. GIS Application on Population Dynamics and Habitat Monitoring of Giant Panda in Wolong, Sichuan. Sichuan J. Zool. 2004, 23, 133-136.

16. Zhang, H.; Cheng, H.; Zhu, Y.; Liu, X.; Li, D. Status and conservation strategy of Giant Panda habitat in Qinling tunnel area of 108 national road. J. Shaanxi Norm. Univ. 2007, 35, 116-119.

17. Fan, J.; Li, J.; Quan, Z.; Wu, X.; Hu, L.; Yang, Q. Impact of road construction on giant panda's habitat and its carrying capacity in Qinling Mountains. Acta Ecol. Sin. 2011, 31, 145-149. [CrossRef]

18. Liu, L.; Liu, X.; Jin, X.; Wang, Z.; Gong, M. Research on the change of Giant Pandas' spatial utilization and road impacts in the Qinling Mountains. Acta Theriol. Sin. 2017, 37, 215-225.

19. An, L.; Liu, J.; Ouyang, Z.; Linderman, M.; Zhou, S.; Zhang, H. Simulating demographic and socioeconomic processes on household level and implications for giant panda habitats. Ecol. Model. 2001, 140, 31-49. [CrossRef]

20. Linderman, M.; An, L.; Bearer, S.; He, G.; Ouyang, Z.; Liu, J. Modeling the spatio-temporal dynamics and interactions of households, landscapes, and giant panda habitat. Ecol. Model. 2005, 183, 47-65. [CrossRef]

21. Ge, Z.; Xing, W.; Li, J.; Yang, W. The impact of firewood collection by local people on the distributing of arbors around the nature reserves: A case study in Wanglang Nature Reserve for Giant Panda (Sichuan). Acta Ecol. Sin. 2006, 26, 97-103.

22. Wang, X.; Xu, W.; Ouyang, Z. Impacts of spatio-temporal changes in agricultural land on Giant Panda habitat: A case study in the Baicaohe Watershed of the Mid-Minshan Mountains. Biodiv. Sci. 2009, 17, 10-18.

23. Wang, C.; Wen, Y.; Hao, C.; Shi, J. A study on farmers' pre-satisfaction and follow-up willingness of returning farmland in the Giant Panda Nature Reserve: A case on 124 households surrounding Shaanxi Changqing Nature Reserve. Resour. Sci. 2010, 32 , 2030-2037.

24. Song, S.; Liu, Q.; Wen, Y. An analysis of determinants of natural resources dependence in the communities surrounding Qinling Giant Panda Protection Area. J. Zhejiang AF Univ. 2016, 33, 130-136.

25. Liu, J.; Miao, H.; Zheng, H.; Ouyang, Z.; Jiang, B. Discussion about the relationship pattern between Wolong Nature Reserve and local community. Acta Ecol. Sin. 2008, 29, 259-271.

26. Chen, H.; Zhu, T.; Maddox, D. Livelihood sustainability and community based co-management of forest resources in China: Changes and improvement. Environ. Manag. 2012, 49, 219-228. [CrossRef]

27. He, K.; Dai, Q.; Gu, X.; Zhang, Z.; Zhou, J.; Qi, D.; Gu, X.; Yang, X.; Zhang, W.; Yang, B.; et al. Effects of roads on giant panda distribution, a mountain range scale evaluation. Sci. Rep. 2019, 9, 1-8. [CrossRef]

28. Huang, Q.; Lothspeich, A.; Hernández-Yáñez, H.; Mertes, K.; Liu, X.; Songer, M. What drove giant panda Ailuropoda melanoleuca expansion in the Qinling Mountains? An analysis comparing the influence of climate, bamboo, and various landscape variables in the past decade. Environ. Res. Lett. 2020, 15, 084036. [CrossRef]

29. Li, J.; Shen, G. The Habitat of Giant Pandas; High Education Press: Beijing, China, 2012; pp. $208-255$.

30. Wang, Z.; Xu, W.; Ouyang, Z.; Liu, J.; Xiao, Y.; Chen, Y.; Zhao, L.; Huang, J. Application of ecological-niche factor analysis in habitat assessment of giant pandas. Acta Ecol. Sin. 2008, 28, 821-828.

31. Luna-Aranguré, C.; Vázquez-Domínguez, E. Of pandas, fossils, and bamboo forests: Ecological niche modeling of the giant panda (Ailuropoda melanoleuca) during the Last Glacial Maximum. J. Mammal. 2021, 102, 718-730. [CrossRef]

32. Clements, T.; Suon, S.; Wilkie, D.S.; Milner-Gulland, E.J. Impacts of protected areas on local livelihoods in Cambodia. World Dev. 2014, 64, 125-134. [CrossRef]

33. Duan, W.; Ma, B.; Sun, B.; Wen, Y. Dependence of the poor on forest resources: Evidence from China. Small-Scale For. 2017, 16, 487-504.

34. Amin, A.; Choumert, J.; Combes, J.L.; Combes-Motel, P.; Schwartz, S. Neighborhood effects in the Brazilian Amazon: Protected area and deforestation. J. Environ. Econ. Manag. 2019, 93, 272-288. [CrossRef]

35. Tang, J.; Swaisgood, R.R.; Owen, M.A.; Zhao, X.; Wei, W.; Pilfold, N.W.; Wei, F.; Yang, X.; Gu, X.; Yang, Z.; et al. Climate change and landscape-use patterns influence recent past distribution of giant pandas. Proc. R. Soc. B Biol. Sci. 2020, 287, 20200358. [CrossRef] [PubMed]

36. Hutchinson, M.F. Interpolation of rainfall data with thin plate smoothing splines I. two dimensional smoothing of data with short range correlation. Geogr. Inf. Decis. Anal. 1998, 2, 153-167. 
37. Xu, X. China Population Spatial Distribution Kilometer Grid Dataset. In Data Registration and Publishing System of Resource and Environmental Science Data Center of Chinese Academy of Sciences; 2017. Available online: http://www.resdc.cn/DOI/DOI.aspx? DOIid=32 (accessed on 11 December 2017).

38. Xu, X. China GDP Spatial Redistribution Kilometer Grid Dataset. In Data Registration and Publishing System of Resource and Environmental Science Data Center of Chinese Academy of Sciences; 2017. Available online: https://www.resdc.cn/DOI/doi.aspx? DOIid=33 (accessed on 11 December 2017).

39. Santos-Hernández, A.F.; Monterroso-Rivas, A.I.; Granados-Sánchez, D.; Villanueva-Morales, A.; Santacruz-Carrillo, M. Projections for Mexico's Tropical Rainforests Considering Ecological Niche and Climate Change. Forests 2021, 12, 119. [CrossRef]

40. Zhang, L.; Ouyang, Z. Exploring the Relationships between Key Ecological Indicators to Improve Natural Conservation Planning at Different Scales. Forests 2019, 10, 32. [CrossRef]

41. Yan, S.; Wang, X.; Cai, Y.; Li, C.; Yan, R.; Cui, G.; Yang, Z. An integrated investigation of spatiotemporal habitat quality dynamics and driving forces in the upper basin of Miyun reservoir, North China. Sustainability 2018, 10, 4625. [CrossRef]

42. Li, M.; Yu, B.; Zheng, B.; Gao, L. Collection of Non-Timber Forest Products in Chinese Giant Panda Reserves: The Effect of Religious Beliefs. Forests 2021, 12, 46. [CrossRef]

43. Li, C.; Connor, T.; Bai, W.; Yang, H.; Zhang, J.; Qi, D.; Zhou, C. Dynamics of the giant panda habitat suitability in response to changing anthropogenic disturbance in the Liangshan Mountains. Biol. Conserv. 2019, 237, 445-455. [CrossRef]

44. Wang, H.; He, M.; Ran, N.; Xie, D.; Wang, Q.; Teng, M.; Wang, P. China's Key Forestry Ecological Development Programs: Implementation, Environmental Impact and Challenges. Forests 2021, 12, 101. [CrossRef]

45. Tang, P.; Chen, F.; Guo, H.; Tian, B.; Wang, X.; Ishwaran, N. Large-area landslides monitoring using advanced multi-temporal InSAR technique over the giant panda habitat, Sichuan, China. Remote Sens. 2015, 7, 8925-8949. [CrossRef]

46. Bai, W.; Huang, Q.; Zhang, J.; Stabach, J.; Hull, V. Microhabitat selection by giant pandas. Biol. Conserv. 2020, $247,108615$. [CrossRef]

47. Ouyang, Z.; Li, Z.; Liu, J.; An, L.; Tan, Y. The recovery processes of giant panda habitat in Wolong Nature Reserve, Sichuan China. Acta Ecol. Sin. 2002, 22, 1840-1849.

48. Yang, B.; Busch, J.; Zhang, L.; Ran, J.; Gu, X.; Zhang, W.; Du, B.; Xu, Y.; Mittermeier, A.R. China's collective forest tenure reform and the future of the giant panda. Conserv. Lett. 2015, 8, 251-261. [CrossRef]

49. Li, Y.; Viña, A.; Yang, W.; Chen, X.; Zhang, J.; Ouyang, Z.; Liang, Z.; Liu, J. Effects of conservation policies on forest cover change in giant panda habitat regions, China. Land Use Policy 2013, 33, 42-53. [CrossRef]

50. Yang, M.; Ouyang, Z.; Xu, W.; Long, Q.; Xie, Q. Assessment of the potential suitable habitat and the actual use habitat of giant pandas in Wolong. J. Sichuan Agric. Univ. 2017, 35, 116-123.

51. Zeng, Z.; Deng, S.; Ren, G.; Zhao, Z.; Shen, G. Climate-induced spatial mismatch may intensify giant panda habitat loss and fragmentation. Biol. Conserv. 2020, 241, 108392. [CrossRef]

52. Zhang, Y.; Mathewson, P.D.; Zhang, Q.; Porter, W.P.; Ran, J. An ecophysiological perspective on likely giant panda habitat responses to climate change. Glob. Chang. Biol. 2018, 24, 1804-1816. [CrossRef] [PubMed]

53. Zhao, C.; Yue, B.; Ran, J.; Moermond, T.; Hou, N.; Yang, X.; Gu, X. Relationship between human disturbance and endangered giant panda Ailuropoda melanoleuca habitat use in the Daxiangling Mountains. Oryx 2017, 51, 146-152. [CrossRef]

54. Ma, B.; Yin, R.; Zheng, J.; Wen, Y.; Hou, Y. Estimating the social and ecological impact of community-based ecotourism in giant panda habitats. J. Environ. Manag. 2019, 250, 109506. [CrossRef]

55. Hull, V.; Zhang, J.; Huang, J.; Zhou, S.; Liu, J. Habitat use and selection by giant pandas. PLoS ONE 2016, 11, e0162266. [CrossRef] [PubMed]

56. Ouyang, Z.; Liu, J.; Xiao, H.; Tan, Y.; Zhang, H. An assessment of giant panda habitat in Wolong Nature Reserve. Acta Ecol. Sin. 2001, 21, 1869-1874.

57. Gong, M.; Yang, Z.; Yang, W.; Song, Y. Giant panda habitat networks and conservation, is this species adequately protected? Wildl. Res. 2010, 37, 531-538. [CrossRef]

58. Jian, J.; Jiang, H.; Jiang, Z.; Zhou, G.; Wang, J. Evaluating the habitat quality of giant panda (Ailuropoda melanoleuca) using habitat suitability index (HSI). Pol. J. Ecol. 2012, 60, 827-837.

59. Hong, M.; Yuan, S.; Yang, Z.; Yang, X.; Gu, X.; Huang, F.; Zhang, Z. Comparison of microhabitat selection and trace abundance of giant pandas between primary and secondary forests in Liziping Nature Reserve, China: Effects of selective logging. Mamm. Biol. 2015, 80, 373-379. [CrossRef]

60. Liu, G.; Guan, T.; Dai, Q.; Li, H.; Gong, M. Impacts of temperature on giant panda habitat in the north Minshan Mountains. Ecol. Evol. 2016, 6, 987-996. [CrossRef]

61. Salick, J.; Ghimire, K.S.; Fang, Z.; Dema, S.; Konchar, M.K. Himalayan alpine vegetation, climate change and mitigation. J. Ethnobiol. 2014, 34, 276-293. [CrossRef]

62. Zhang, J.; Hull, V.; Xu, W.; Liu, J.; Ouyang, Z.; Huang, J.; Wang, X.; Li, R. Impact of the 2008 Wenchuan earthquake on biodiversity and giant panda habitat in Wolong Nature Reserve, China. Ecol. Res. 2011, 26, 523-531. [CrossRef]

63. Zheng, W.; Ran, J.; Li, B.; Gu, X.; Shang, T. Effect of the Wenchuan earthquake on habitat use patterns of the giant panda in the Minshan Mountains, southwestern China. Biol. Conserv. 2012, 145, 241-245. [CrossRef]

64. Zhou, J. The Study on the Quality Evaluation System of Giant Panda Habitat. Ph.D. Thesis, Beijing Forestry University, Beijing, China, 2007. 
65. Lai, X.; Zhou, W.; Gao, H.; Wang, M.; Nie, Y. Impact of sympatric carnivores on den selection of wild giant pandas. Zool. Res. 2020, 41, 273-280. [CrossRef] [PubMed]

66. Ashrafzadeh, M.R.; Khosravi, R.; Adibi, M.A.; Taktehrani, A.; Wan, H.Y.; Cushman, S.A. A multi-scale, multi-species approach for assessing effectiveness of habitat and connectivity conservation for endangered felids. Biol. Conserv. 2020, 245, 108523. [CrossRef]

67. Qiao, M.; Connor, T.; Shi, X.; Huang, J.; Huang, Y.; Zhang, H.; Ran, J. Population genetics reveals high connectivity of giant panda populations across human disturbance features in key nature reserve. Ecol. Evol. 2019, 9, 1809-1819. [CrossRef]

68. Luo, L.; Pu, D.; Qiu, L.; Chen, Y.; Deng, Y.; Li, G.; Han, H.; Zhou, H.; Wei, W. Impact of grazing on giant pandas and their habitat and implication for conservation. J. Guizhou Norm. Univ. (Nat. Sci.) 2019, 37, 52-57.

69. Yang, H. China's natural forest protection program, progress and impacts. For. Chron. 2017, 93, 113-117. [CrossRef]

70. Khosravi, R.; Hemami, M.R.; Malakoutikhah, S.; Ashrafzadeh, M.R.; Cushman, S.A. Prey availability modulates predicted range contraction of two large felids in response to changing climate. Biol. Conserv. 2021, 255, 109018. [CrossRef]

71. Shen, G.; Xie, Z.; Feng, C.; Xu, W.; Guo, K. Influence of the Wenchuan Earthquake on giant panda habitats and strategies for restoration. Chin. J. Plant Ecol. 2008, 32, 1417-1425.

72. Di, B.; Zeng, H.; Zhang, M.; Ustin, L.S. Quantifying the spatial distribution of soil mass wasting processes after the 2008 earthquake in Wenchuan, China. Remote Sens. Environ. 2010, 114, 761-771. [CrossRef]

73. Deng, X.; Jiang, Q.; Yang, G. Impacts of the Wenchuan Earthquake on the giant panda nature reserves in China. J. Mt. Sci. 2010, 7, 197-206. [CrossRef]

74. Andrés, V.; Liu, J. Hidden roles of protected areas in the conservation of biodiversity and ecosystem services. Ecosphere 2017, 8, e01864.

75. Wang, X.; Xu, W.; Ouyang, Z. Integrating population size analysis into habitat suitability assessment, implications for giant panda conservation in the Minshan Mountains, China. Ecol. Res. 2009, 24, 1101-1109. [CrossRef]

76. Li, B.; Pimm, S.L. China's endemic vertebrates sheltering under the protective umbrella of the giant panda. Conserv. Biol. 2016, 30, 329-339. [CrossRef] [PubMed]

77. Kang, D.; Li, J. A new strategy for giant panda protection. Biodivers. Conserv. 2018, 27, 1039-1040. [CrossRef]

78. Ma, B.; Cai, Z.; Zheng, J.; Wen, Y. Conservation, ecotourism, poverty, and income inequality: A case study of nature reserves in Qinling, China. World Dev. 2018, 115, 236-244. [CrossRef]

79. Liu, J.; Ouyang, Z.; Taylor, W.W.; Groop, R.; Tan, Y.; Zhang, H. A framework for evaluating the effects of human factors on wildlife habitat, the case of giant pandas. Conserv. Biol. 1999, 13, 1360-1370. [CrossRef] 